\title{
Characterization and Differentiation
}

of Heterocyclic Isomers. Part 2.*

Mass Spectrometry and Molecular

Orbital Calculations on

\section{Pyrrolol1,2-a][1,4]benzodiazepin-4-one, -6-one, and -4,6-dione}

\author{
Gianluca Giorgi \\ Centro Interdipartimentale di Analisi e Determinazioni Strutturali della Università di Siena, via P.A. Mattioli, \\ 10-53100 Siena, Italy \\ Maurizio Anzini, Andrea Cappelli, Federico Corelli, and Salvatore Vomero \\ Dipartimento Farmaco Chimico Tecnologico della Università di Siena, via Banchi di Sotto, 55-53100 Siena, Italy
}

Pyrrolo[1,2-a][1,4]benzodiazepin-4-one (1), -6-one (2), and -4,6-dione (3), which are starting materials for the synthesis of pharmacologically interesting compounds that are active as neurotropic agents, have been characterized in the gas phase. The application of different mass spectrometric techniques, such as electron ionization, high-resolution, and tandem mass spectrometry, has allowed the structural characterization and differentiation of their molecular ions and most abundant fragment ions formed in the source. In particular, the two positional isomers 1 and 2 produce quite different mass spectra, and their molecular and the most intense fragment ions yield different metastable mass-analyzed ion kinetic energy spectra. Furthermore, high-resolution mass spectrometry and accurate mass measurements have revealed different elemental compositions and abundances for isobaric fragment ions produced by isomers 1 and 2 . From these data and from the comparison with those relevant to compound 3 , it has been possible to evaluate the influence of the position of the carbonyl group on the fragmentation pathways.

Semiempirical molecular orbital calculations carried out by both the modified neglect of differential overlap and Austin 1 methods have provided useful information on the characterization of the neutrals as well as the molecular ions of compounds 1-3. (J Am Soc Mass Spectrom 1996, 7, 653-663)

\section{Introduction}

$\mathrm{T}$ he structural characterization of a compound and the differentiation of isomers are crucial problems for chemists and biochemists. In particular, in the pharmaceutical and pharmacological fields, it is essential to identify a given molecule unambiguously, both of natural or synthetic origin, and to distinguish it among analogous derivatives and isomers. The characterization of structural isomers by mass spectrometry can be carried out through the study of the positional effects of a given substituent on metastable or colli-

Address reprint requests to Dr. Gianluca Giorgi, Centro Interdipartimentale di Analisi e Determinazioni Strutturali, Università di Siena, via P. A. Mattioli, 10, 53100 Siena, Italy.

*Part 1 of this article is Giorgi, G.; Ponticelli, F.; Czira, G.; Vékey, K. J. Am. Soc. Mass Spectrom. 1995, 6, 962-971. sion-induced dissociation (CID) processes of the molecular ion [1, 2]. Some cases that may occur include: (1) each isomer follows fragmentation pathways that differ in the mass-to-charge ratio values and/or abundances of the ions; (2) one isomer converts into another owing to the ionization process; (3) different isomers produce a common intermediate before fragmenting. Although in the first case it is possible to distinguish each isomer, the latter two cases do not allow differentiation. In addition to the characterization of molecular ion decompositions, the study of metastable and/or CID spectra of fragment ions produced in the source region may give further information for the differentiation of isomers. Finally, if different isomers yield isobaric fragment ions which may be produced by competitive fragmentation pathways, it is interesting to determine their elemental compositions and abundances through high resolution mass spectrometry and accurate mass measurements. 
The identification and characterization of isomers is a fascinating problem in the chemistry of heterocyclic compounds where positional isomers may differ either in the position of endocyclic groups or heteroatoms, and/or in that of exocyclic substituents. Benzodiazepines are heterocycles of great interest in consequence of the wide range of their pharmacological activities [3]. In particular, changes in the benzodiazepine nucleus as well as in the substituents can modulate the drug activity, which produces a finetuning of the biological effects. Several analytical techniques, such as nuclear magnetic resonance, UV and infrared spectroscopies have been employed extensively to characterize benzodiazepines [4].

Because of its high sensitivity and specificity, mass spectrometry has been used widely to characterize several 1,4- and 1,5- benzodiazepine derivatives [5-9], as well as to elucidate their biotransformation pathways and pharmacokinetics [10, 11]. Mass spectrometric characterization of fused benzodiazepines, such as imidazo- [12, 13], pyrrolo- [14], s-triazolo-benzodiazepines [15], and dibenzodiazepines [16-18] also has been reported. Most of these studies were carried out by low-rcsolution electron ionization; only sparse tandem mass spectrometry studies have been published.

In the course of research aimed at finding new anxiolitic agents, it was found that the tricyclic pyrrolo[1,2-a][1,4]benzodiazepine system possesses highly lipophilic and neurotropic properties. The introduction of appropriate substituents on this heterocycle yields biologically active compounds [19]. We wish to report here on the characterization by electron ionization, high-resolution, and tandem mass spectrometry of 5,6-dihydro-4H-pyrrolo[1,2-a][1,4]benzodiazepin-4one (1), 4,5-dihydro-6H-pyrrolo[1,2-a][1,4]benzodiazepin-6-one (2), and the 4,6-dione derivative of 1 (3) (Scheme I), which are starting materials for the synthesis of new compounds that are pharmacologically active as serotonin $5-\mathrm{HT}_{1 \mathrm{~A}}$ receptor ligands [20].

Compounds 1 and 2 are positional isomers. Their characterization and differentiation are particularly interesting and have been carried out in the present study by low- and high-resolution and tandem mass spectrometry on both the molecular and the most abundant fragment ions formed in the source. Molecular orbital calculations on both neutrals 1-3 and their molecular ions also have been carried out. Among various semiempirical methods available, the modified neglect of differential overlap (MNDO) method [21] and the Austin method 1 (AM1) [22] have been chosen and their results are compared.

\section{Experimental}

\section{Material and Mass Spectrometry}

Compounds 1-3 have been synthesized and purified as previously reported [23]. Deuterium labeling at the - NH position was obtained by dissolving $1 \mathrm{mg}$ of

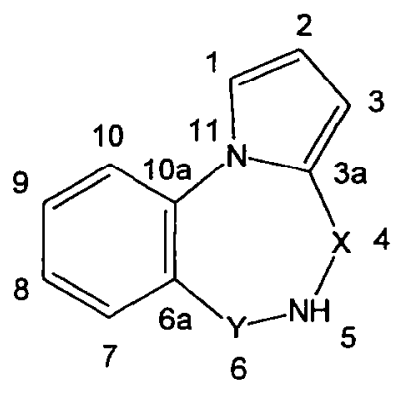

\begin{tabular}{ccc}
\hline Compound & $\mathbf{X}$ & $\mathbf{Y}$ \\
\hline 1 & $\mathrm{CO}$ & $\mathrm{CH} 2$ \\
2 & $\mathrm{CH} 2$ & $\mathrm{CO}$ \\
3 & $\mathrm{CO}$ & $\mathrm{CO}$ \\
\hline
\end{tabular}

Scheme I

each compound in $\mathrm{CD}_{3} \mathrm{OD}$ and $\mathrm{CDCl}_{3}$ (Fluka, Chemie AG, Buchs, Switzerland, NMR grade) and allowing the solution to stand at room temperature for some days.

Mass spectra were measured on a double focusing VG 70-250S mass spectrometer (VG Analytical Ltd., Manchester, UK) that operated in the electron ionization mode at $70 \mathrm{eV}$, emission current $0.2 \mathrm{~mA}$, with a source temperature of $180^{\circ} \mathrm{C}$. The accelerating voltage was $8 \mathrm{kV}$ and the resolution was $1000 \mathrm{M} / \Delta M(10 \%$ valley). The samples were introduced via the direct inlet system without heating. Daughter and parent ion spectra as well as constant neutral mass loss scans were performed to detect metastable decompositions that occurred in the first field-free region by appropriate linked scans. Data acquisition and analysis of the spectra were performed with a VG 11-250J data system equipped with a Digital PDP 11/83 minicomputer (Digital Equipment Corp., Maynard, MA). Highresolution mass measurements were performed at resolution 8000 or $20,000 M / \Delta M$ (10\% valley; see text) under the data system control against perfluorokerosene standard (Fluka, Chemie AG).

Metastable-mass-analyzed ion kinetic energy (MIKE) spectra, E/Q-MIKE spectra, and $Q$ scans were carried out with a VG ZAB 2-SEQ BEqQ hybrid instrument (VG Analytical Ltd., Manchester, UK) coupled with an OPUS 2000 data system, under the same experimental conditions reported in the preceding text. The reproducibility of the relative peak abundances in replicate measurements of tandem mass spectra was within $10 \%$. 


\section{Semiempirical Calculations}

Semiempirical molecular orbital calculations were performed on compounds 1-3, both on neutral species and on molecular ions. All calculations were carried out by using the program MOPAC version 4.0 [24] implemented on a Digital VAX 6610 computer and the methods MNDO [21] and AM1 [22]. The molecular geometry was fully optimized without any constraints. The use of the unrestricted Hartree-Fock formalism on the open-shell systems gave severe spin contamination with a calculated $\left\langle S^{2}\right\rangle$ value higher than 1.2 (expected $\left\langle S^{2}\right\rangle=0.75$ for a doublet). In these cases, the open-shell restricted Hartree-Fock procedure should be preferred, but it is available only with ab initio methods. Therefore the restricted Hartree-Fock formalism [25] and the half electron method were used for calculations on closed-and open-shell systems, respectively.

\section{Results and Discussion}

\section{Mass Spectrometry}

Isomers $\mathbf{1}$ and 2 . The mass spectra produced in the source region by isomers 1 and 2 are reported in Figure 1. Both heterocycles show high stability under electron ionization as shown by the relative intensities of their molecular ions $\left(\mathrm{m} / z\right.$ 198): $[\mathrm{M}]^{+\cdot}$ is the base peak in the spectrum of 2 , whereas its relative intensity is $65 \%$ in the mass spectrum of 1 .

The two isomers show common isobaric fragment ions, but remarkable differences occur in their relative intensities and compositions, as shown by high-resolution mass spectrometry (HRMS). Compound 2 shows a highly favored loss of $\mathrm{H}^{\cdot}$ that yields a $[\mathrm{M}-\mathrm{H}]^{+}$ion with a relative intensity of $70 \%$. It is reasonable to assume that the hydrogen radical is lost from the methylene group in position 4. A role of the $H(N)$ atom may be excluded on the basis of the mass and MIKE spectra of the $N(4)-d_{1}$ derivative of 2 , which show the prevailing loss of hydrogen with respect to that of deuterium. This is a typical fragmentation process of lactams in which a hydrogen radical from the methylene $\alpha$ to the nitrogen atom is involved [26]. Some examples of loss of hydrogen from 1,4-benzodiazepin-2-ones that yield a very intense $[\mathrm{M}-\mathrm{H}]^{+}$ion have been reported previously [27]. By analogy with what is observed in chemical reactions in solution [28], it has been assumed that this process induces rearrangements that consist of ring contractions that yield quinoline or isoindole derivatives [27]. On the other hand, the loss of a hydrogen radical is quite scarce both for isomer 1, where the methylene group is in position 6, and for compound 3, in which this group has been replaced by a carbonyl.

Common fragment ions formed in the source for 1 (Figure 2) and 2 (Figure 3) are at $m / z 170$ and 169, which correspond to losses of 28 and $29 u$ from the molecular ion, respectively. Different compositions and
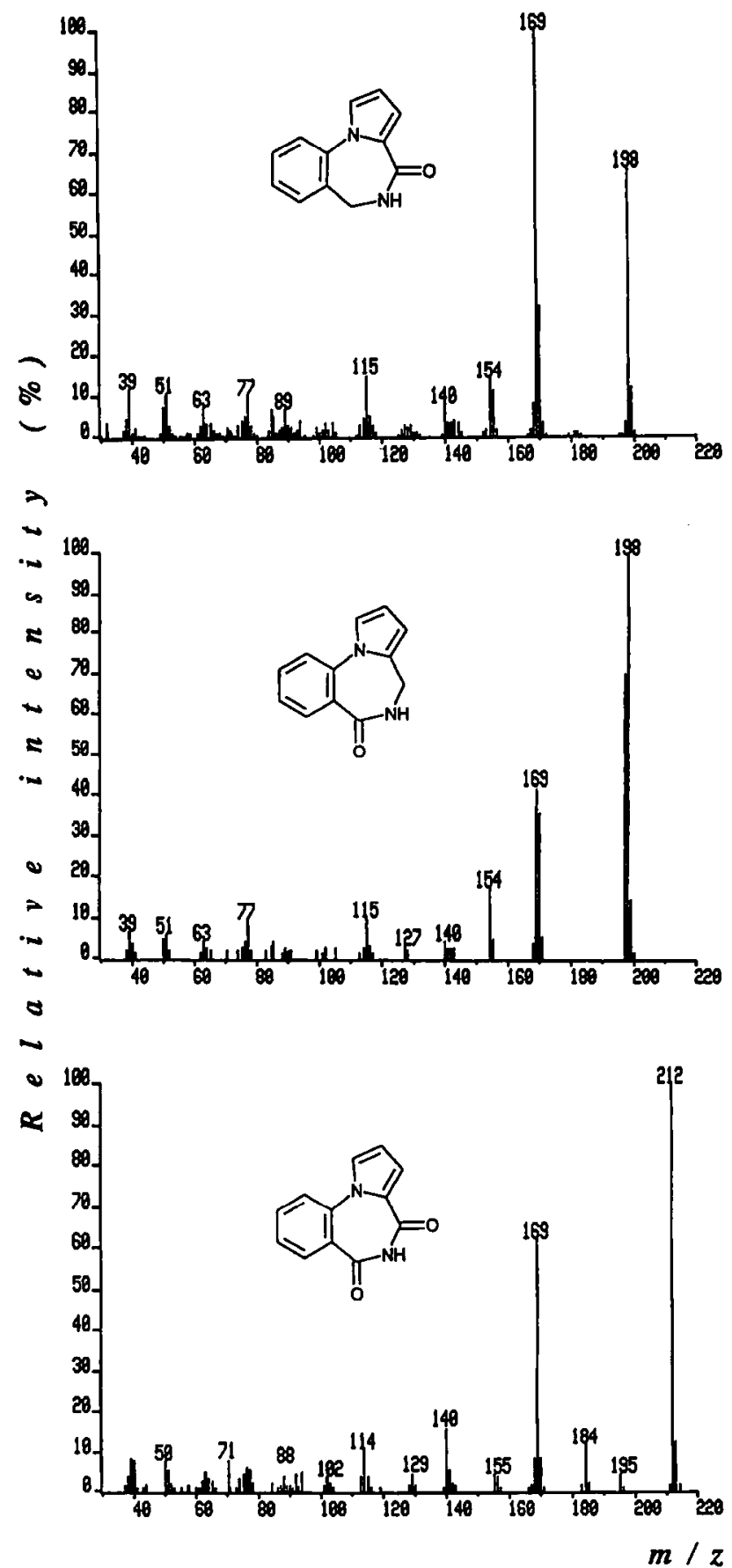

Figure 1. EI + mass spectra produced in the source region by compounds 1 (top), 2 (middle), and 3 (bottom).

parent ions are possible for these ionic species. Highresolution mass spectra and accurate mass measurements of ions formed in the source (Table 1) can shed light on their elemental composition, whereas tandem mass spectrometry experiments can explain their origin.

With regard to ion $[M-28](m / z 170)$, when the resolution is $8000 \mathrm{M} / \Delta \mathrm{M}(10 \%$ valley), a single peak and an unresolved doublet are present in the spectrum of 1 . The single peak is due to the loss of ${ }^{\circ} \mathrm{CHNH}$ from the molecular ion, whereas two different ions might 


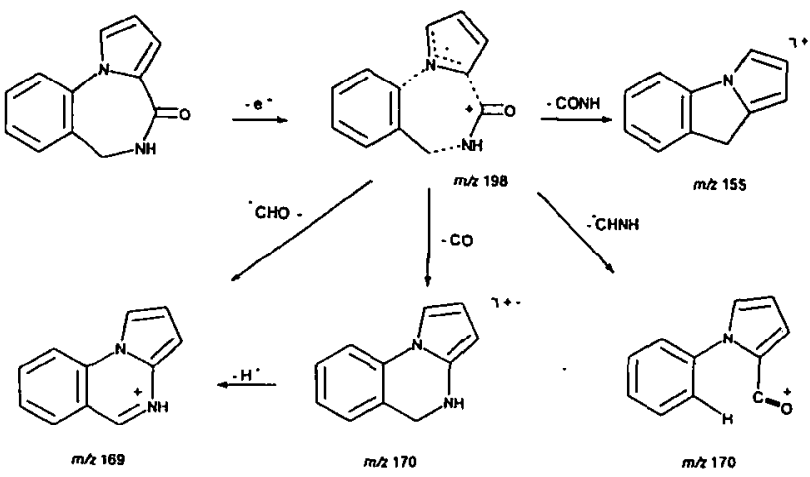

Figure 2. Fragmentation pathways of high internal energy ions for compound 1. The bond types of the molecular ion reflect the bond orders obtained by MNDO calculations (see text).

contribute to the doublet: $\left[{ }^{13} \mathrm{C}^{12} \mathrm{C}_{10} \mathrm{H}_{9} \mathrm{~N}_{2}\right]^{+}$(calculated $m / z 170.0799$ ) and $\left[\mathrm{C}_{11} \mathrm{H}_{10} \mathrm{~N}_{2}\right]^{+}$(calculated $\mathrm{m} / \mathrm{z}$ 170.0844). A theoretical resolution of about $40,000 M / \Delta M$ is necessary to separate them. However, resolution of $20,000 M / \Delta M$ allowed the two accurate masses to be calculated correctly, which confirmed the two supposed species. It follows that in compound 1 the species $[\mathrm{M}-\mathrm{CO}]^{+\cdot}$ and $[\mathrm{M}-\mathrm{CHNH}]^{+}$contribute to the ion $[\mathrm{M}-28]$, with an intensity ratio 3:1. On the other hand, 2 produces an ion [M - 28] entirely due to the loss of $\mathrm{CHNH}$. For 7-chloro-5-phenyl-1,3-dihydro2H-1,4-benzodiazepin-2-one, high-resolution mass measurements revealed that the ion [M - 28] is formed by a doublet that consists of $[\mathrm{M}-\mathrm{CO}]^{+\cdot}$ and $[(\mathrm{M}-$ $\mathrm{H})-\mathrm{HCN}]^{+}$; the latter ion is about 20 times as intense [27]. Similarly, the molecular ions of 5-phenyl-1,4-benzodiazepin-2-ones lose the isobaric fragments ${ }^{\circ} \mathrm{CHNH}$

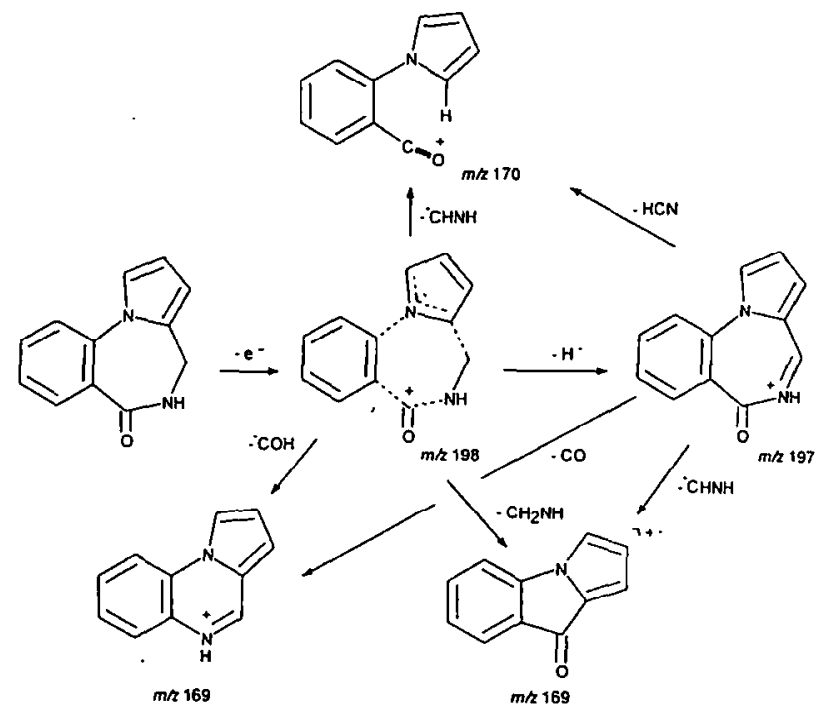

Figure 3. Fragmentation pattern of ions formed in the source for compound 2. The bond types of the molecular ion reflect the bond orders obtained by MNDO calculations (see text).

and $\mathrm{CO}$, which produces $[\mathrm{M}-\mathrm{CHNH}]^{+}$as a major component [29].

With regard to ion $[M-29](m / z 169)$, the highresolution mass spectrum of 1 shows a single peak attributable to the loss of $\mathrm{CHO}$ from the molecular ion. On the other hand, in the case of 2 a doublet formed by $\left[\mathrm{M}-\mathrm{CH}_{2} \mathrm{NH}\right]^{+\cdot}$ and $[\mathrm{M}-\mathrm{CHO}]^{+}$is present, with an intensity ratio $1: 5$ for the two species. Previous data have shown that the molecular ion of 3H-1,4-benzodiazepin-2,5- $(1 \mathrm{H}, 4 \mathrm{H})$-dione loses $\mathrm{CH}_{2} \mathrm{NH}$ [6], whereas that of 5,6-dihydro-7Hpyrrolo[1,2-d][1,4]benzodiazepin-6-one fragments by

Table 1. Accurate mass data (error $\times 10^{3}$ ) for singly charged ions from compounds 1-3

\begin{tabular}{|c|c|c|c|}
\hline \multirow[b]{2}{*}{$\operatorname{lon}^{a}$} & \multicolumn{3}{|c|}{ Compound } \\
\hline & 1 & 2 & 3 \\
\hline$\left[\mathrm{M}^{+\cdot}\right.$ & $198.0799(-0.6)$ & $198.0789(0.4)$ & $212.0580(0.5)$ \\
\hline$[\mathrm{M}-\mathrm{H}]^{+}$ & & $197.0710(0.5)$ & \\
\hline$[\mathrm{M}-\mathrm{OH}]^{+}$ & & & $195.0553(0.6)$ \\
\hline$[\mathrm{M}-\mathrm{CO}]^{+\cdot}$ & $170.0840(0.4)$ & & $184.0629(0.8)$ \\
\hline$[\mathrm{M}-\mathrm{CHNH}]^{+}$ & $170.0606(0.0)$ & $170.0610(-0.4)$ & \\
\hline$\left[\mathrm{M}-\mathrm{CHO}^{+}\right.$ & $169.0770(-0.5)$ & $169.0768(-0.3)$ & \\
\hline$\left[\mathrm{M}-\mathrm{CH}_{2} \mathrm{NH}\right]^{+\cdot}$ & & $169.0531(-0.3)$ & \\
\hline$[\mathrm{M}-\mathrm{CONH}]^{+\cdot}$ & $155.0729(0.5)$ & $155.0726(0.9)$ & $169.0529(-0.1)$ \\
\hline$[\mathrm{M}-2 \mathrm{CO}]^{+\cdot}$ & & & $156.0680(0.7)$ \\
\hline$\left[\mathrm{C}_{11} \mathrm{H}_{7} \mathrm{~N}_{2}\right]^{+}$ & & & $155.0609(0.0)$ \\
\hline$\left[\mathrm{C}_{11} \mathrm{H}_{8} \mathrm{~N}\right]^{+}$ & $154.0654(-0.2)$ & $154.0655(-0.1)$ & \\
\hline$\left[\mathrm{C}_{10} \mathrm{H}_{6} \mathrm{~N}\right]^{+}$ & $140.0496(0.4)$ & $140.0493(0.8)$ & $140.0494(0.6)$ \\
\hline$\left[\mathrm{C}_{9} \mathrm{H}_{7} \mathrm{~N}\right]^{+\cdot}$ & & & $129.0580(-0.2)$ \\
\hline$\left[\mathrm{C}_{8} \mathrm{H}_{5} \mathrm{~N}_{2}\right]^{+}$ & & & $129.0456(-0.3)$ \\
\hline$\left[\mathrm{C}_{9} \mathrm{H}_{7}\right]^{+}$ & $115.0539(0.9)$ & $115.0544(0.3)$ & \\
\hline$\left[\mathrm{C}_{9} \mathrm{H}_{6}\right]^{+\cdot}$ & & & $114.0470(0.0)$ \\
\hline$\left[\mathrm{C}_{7} \mathrm{H}_{5}\right]^{+}$ & $89.0395(-0.3)$ & & \\
\hline
\end{tabular}

${ }^{\mathrm{a}}$ Relative abundances of isobaric ions: $1,[\mathrm{M}-\mathrm{CO}]^{+\cdot} 23.3,[\mathrm{M}-\mathrm{CHNH}]^{+} 7.8 \% ; 2,[\mathrm{M}-\mathrm{CHO}]^{+} 38.4,\left[\mathrm{M}-\mathrm{CH}_{2} \mathrm{NH}^{+\cdot} 7.8 \% ; 3,\left[\mathrm{C}_{9} \mathrm{H}{ }_{7} \mathrm{~N}\right]^{+\cdot}\right.$ 2.3. $\left[\mathrm{C}_{8} \mathrm{H}_{5} \mathrm{~N}_{2}\right]^{+} 1.1 \%$ 
loss of $\mathrm{CHO}$ to give a well-stabilized pyrroloquinazoline cation [30].

To determine parent-daughter relationships among the various ions, tandem mass spectrometry experiments have been carried out. The MIKE spectrum of 1 (Figure 4, top) shows three intense metastable peaks: one produced by the loss of a hydrogen radical at $\mathrm{m} / \mathrm{z}$ 197, a flat-topped peak at $m / z 170$ (inset in Figure 4, top), and another large peak at $m / z 155$, which correspond to losses of $\mathrm{CO}$ and $\mathrm{CONH}$, respectively. The kinetic energy releases measured at half peak height, $T_{0.5}$ [31], associated with the latter two decompositions are 385 and $280 \mathrm{meV}$, respectively. These values indicate high reverse activation energies and suggest that the two fragmentations involve rearrangements with the formation of stable radical cations [1].

The MIKE spectrum of compound 2 (Figure 4, middle) is significantly different from that produced by its isomer 1 . It is dominated by a peak at $m / z 197$, due to the loss of a hydrogen radical and a multiplet centered at $m / z$ 170. By linking the electrostatic sector with the quadrupole analyzer, a better resolution on daughter ions can be achieved. This improved resolution has allowed the metastable peak to be resolved into three components at $m / z 171,170$, and 169; the former component is the most intense (inset in Figure 4, middle). On the basis of high-resolution data, these ions would be produced by losses of $\mathrm{HCN},{ }^{\circ} \mathrm{CHNH}$, and $\mathrm{CH}_{2} \mathrm{NH} /{ }^{\circ} \mathrm{CHO}$ from the molecular ion. The kinetic energy releases associated with these processes can be estimated to be less than $100 \mathrm{meV}$, which suggests that simple bond cleavages are involved. Minor metastable peaks at $\mathrm{m} / \mathrm{z} 180$ and 155, which correspond to losses of a water molecule and $\mathrm{CONH}$, respectively, are also present.

Metastable decompositions of the molecular ion in the third field-free region also were investigated by selecting the precursor ion by the two sectors and scanning the quadrupole analyzer (Figure 5). The spectra resemble those obtained by MIKES with an expected higher resolution on both the main beam and daughter ions. For 1 (Figure 5, top) the metastable decomposition that yields $[\mathrm{M}-\mathrm{CONH}]^{+\cdot}$ seems to prevail slightly with respect to the decomposition that produces [M-28]. Minor metastable peaks at $\mathrm{m} / \mathrm{z}$ 169 and 171, which are not well evidenced in the MIKE spectra, are also present. For isomer 2, the Q-spectrum (Figure 5, bottom) is quite similar to the E/Q-MIKE spectrum with regard to both the abundances and the mass-to-charge ratio values of the ions.

The MIKE spectrum of the $[\mathrm{M}-\mathrm{H}]^{+}$fragment ion $(\mathrm{m} / \mathrm{z}$ 197) formed in the source from isomer 2 shows peaks at $m / z 179,170,169$, and 154 with relative intensities equal to $7.7,100,11.6$, and $3.1 \%$, respectively, that can be attributed to the losses of a water molecule, $\mathrm{HCN}, \mathrm{CO} /{ }^{\circ} \mathrm{CHNH}$, and $\mathrm{CONH}$, respectively. It follows that the ions at $m / z 170$ and 169, present in the mass spectrum, may be produced as

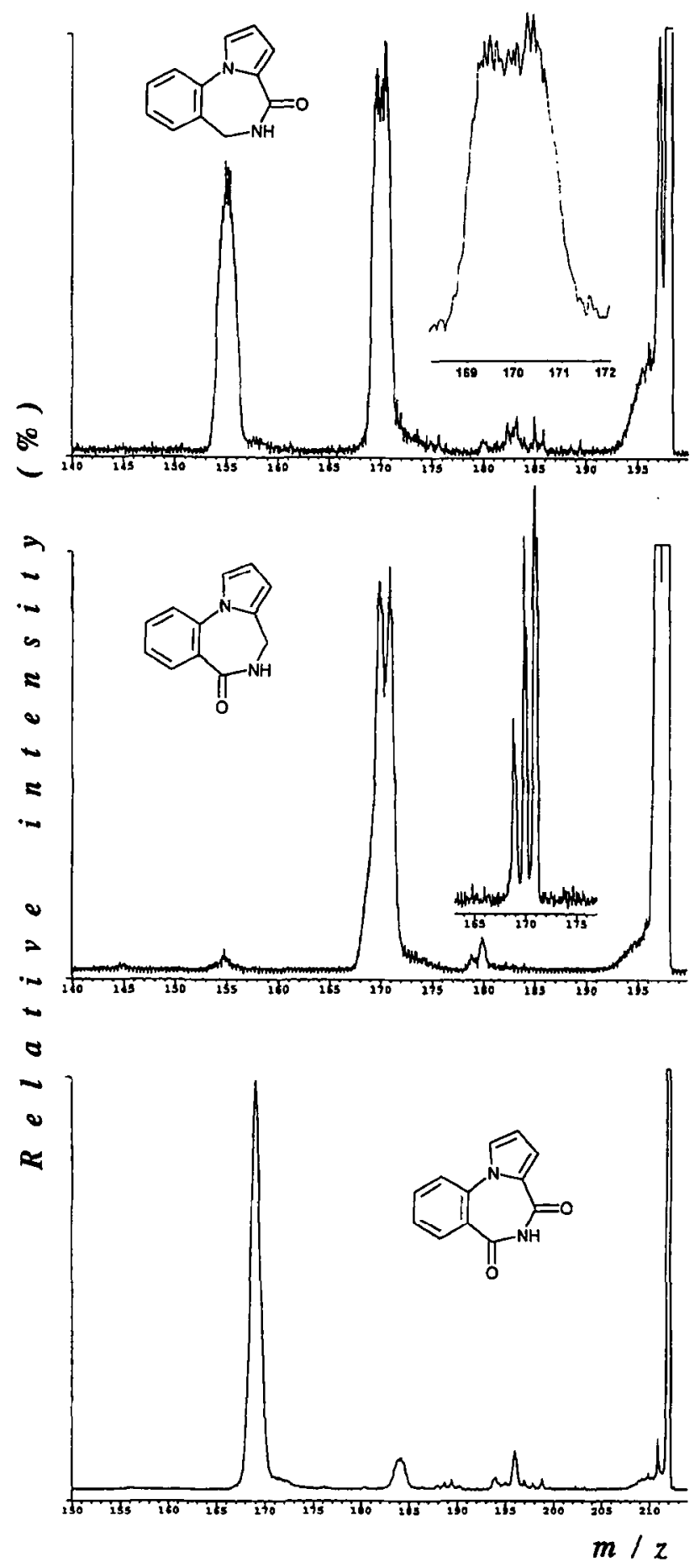

Figure 4. Metastable MIKE spectra of $\mathrm{M}^{+\cdot}$ produced from isomers 1 (top) and 2 (middle), and compound 3 (bottom). The peak shape of the ion [M -28 ] produced by 1 is reported in the inset at the top. For compound 2 a portion of the E/Q spectrum is reported in the inset in the middle.

primary fragmentation by both the molecular and the $[\mathrm{M}-\mathrm{H}]^{+}$ions.

Owing to the observation that, for the two isomers, different isobaric ionic species contribute to the ion [M - 28] (Table 1), tandem mass spectrometry experiments also were carried out on this fragment ion to 


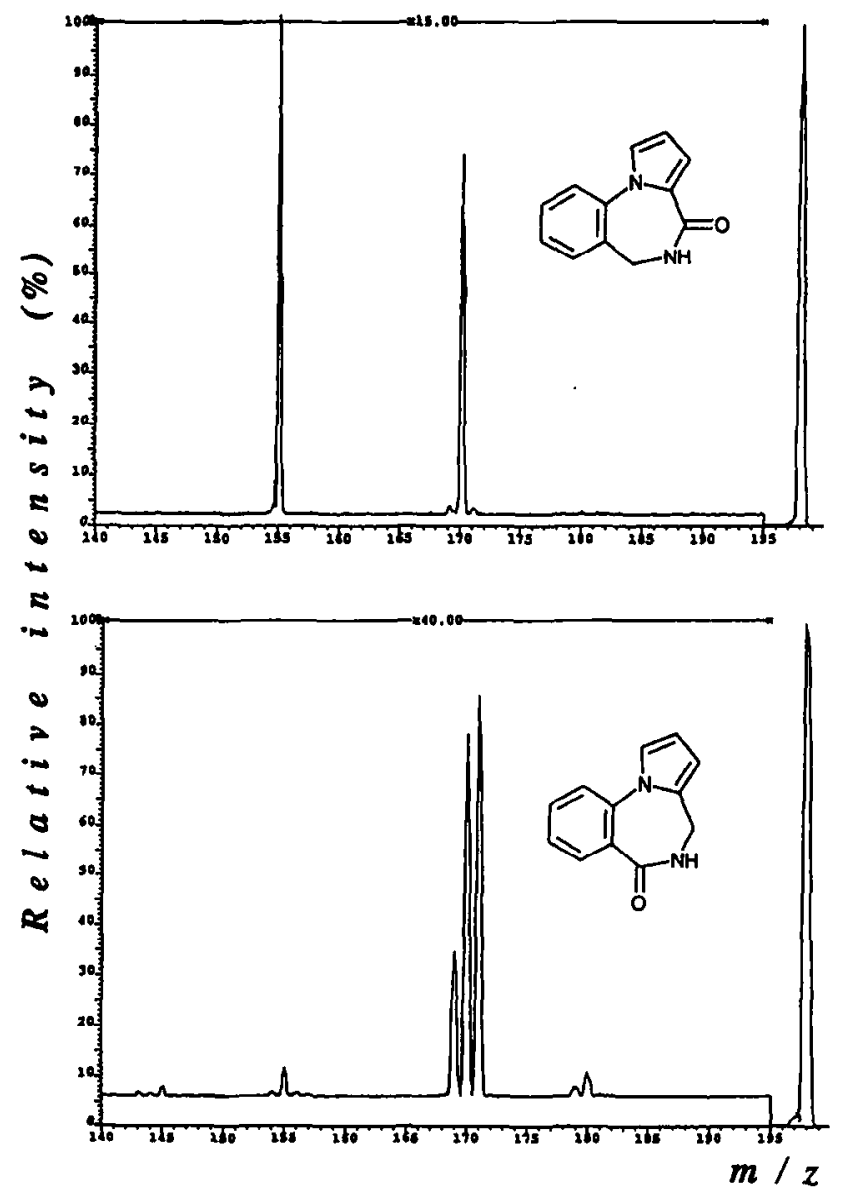

Figure 5. Mass spectra obtained by $\mathrm{Q}$ scans of $\mathrm{M}^{+\cdot}$ produced from isomers 1 (top) and 2 (bottom).

confirm different behavior for compounds 1 and 2 (Figure 6). The MIKE spectrum of the [M - 28] ion $(\mathrm{m} / z 170)$ formed in the source from isomer 1 ([M $\mathrm{CO}]^{+\cdot} /[\mathrm{M}-\mathrm{CHNH}]^{+} 3: 1$; Figure 6 , top), in addition to the conspicuous loss of a hydrogen radical, shows an unresolved doublet with an intensity about three times that of a peak at $m / z 115$. E/Q linked scans have allowed resolution of the multiple peak into two single peaks at $m / z 143$ and 142 (inset in Figure 6, top) that correspond to the losses of 27 and $28 \mathrm{u}$, respectively. The peak at $m / z 115$ reasonably may be attributed to two successive rapid reactions, whose overall kinetic is faster than the flight time of the ions in the second field-free region, which involve the losses of $27+28$ or $28+27 \mathrm{u}$ that yield the ion $\left[\mathrm{C}_{9} \mathrm{H}_{7}\right]^{+}$.

The $[\mathrm{M}-28]$ ion from isomer 2 (Figure 6, middle) produces a quite different MIKE spectrum with respect to the isobaric ion from isomer 1 . In fact the loss of a hydrogen radical and that of $28 \mathrm{u}$ are processes of comparable intensities; the former process prevails slightly. It is noteworthy that, in contrast with isomer 1 , in the region of $m / z \quad 140-145$ only a single peak at $m / z 142$ is present (inset in Figure 6, middle) and it is due to the loss of CO. This is in good agreement with the high-resolution data and accurate mass measurements that attributed the $[M-28]$ ion $(m / z 170)$ from
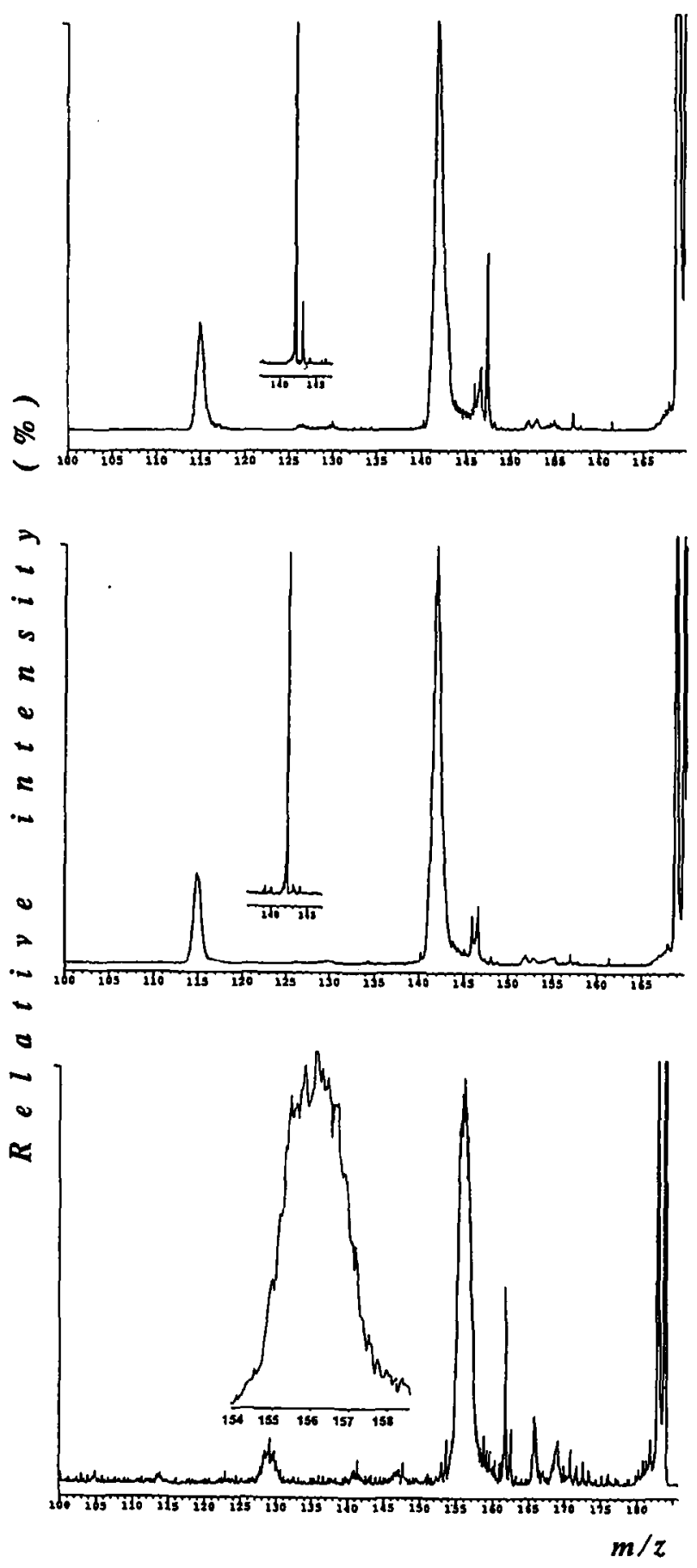

Figure 6. MIKE spectra of [M - 28] fragment ions from isomers 1 (top), 2 (middle), and 3 (bottom). For isomers 1 and 2 a portion of the $E / Q$ spectrum is reported in the insets at the top and at the middle, respectively. The peak shape of the ion at $m / z 156$, produced by 3 , is reported in the inset at the bottom.

isomer 2 entirely to $[\mathrm{M}-\mathrm{CHNH}]^{+}$, which directly and reasonably cannot lose $27 \mathrm{u}$. As observed for isomer 1, a metastable peak at $m / z 115$ is also present.

Tandem mass spectrometry also has been extended to the study of the metastable decompositions of the fragment ions [M - 29] formed in the source (Figure 7). In this case, the different elemental compositions between the $[\mathrm{M}-29]$ ions produced by the isomers 1 


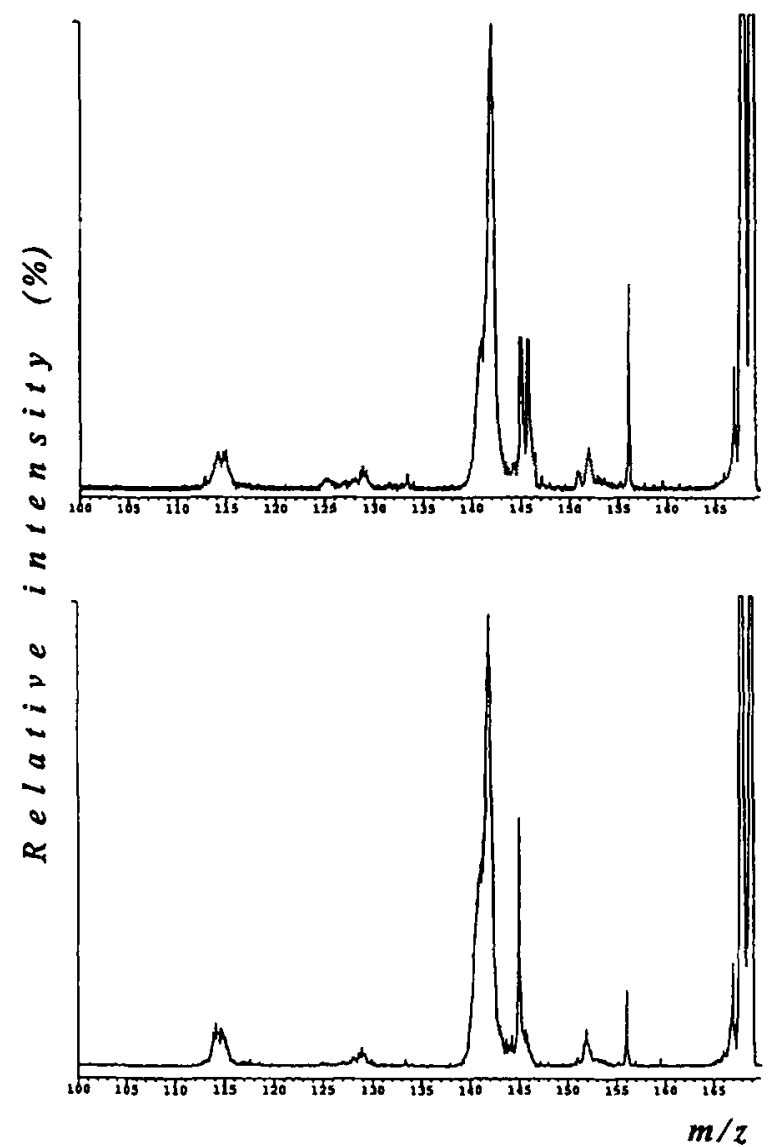

Figure 7. MIKE spectra of $[M-29](m / z$ 169) fragment ions from isomer 1 (top) and 2 (bottom).

and 2 are not reflected in their MIKE spectra, which are quite similar. Both are dominated by the loss of a hydrogen radical and by a doublet at $\mathrm{m} / \mathrm{z} 141$ and 142 due to the losses of 27 and $28 \mathrm{u}$, respectively. The intensity ratios of the two ions are 3:1 and 2:1 in the case of isomers 1 and 2, respectively. A further peak at $m / z 115$ is present for both isomers.

Compound 3. In the mass spectrum obtained in the source for compound 3 (Figure 1, bottom) the molecular ion $(m / z 212)$ is the base peak. Most of the fragmentations of high internal energy ions produced in the source involve loss of neutral species, in particular, $\mathrm{C}_{2} \mathrm{H}_{2}, \mathrm{HCN}, \mathrm{CO}$, and $\mathrm{CONH}$, which makes the mass spectrum dominated by radical ions. Tandem mass spectrometry experiments to detect loss of neutrals are

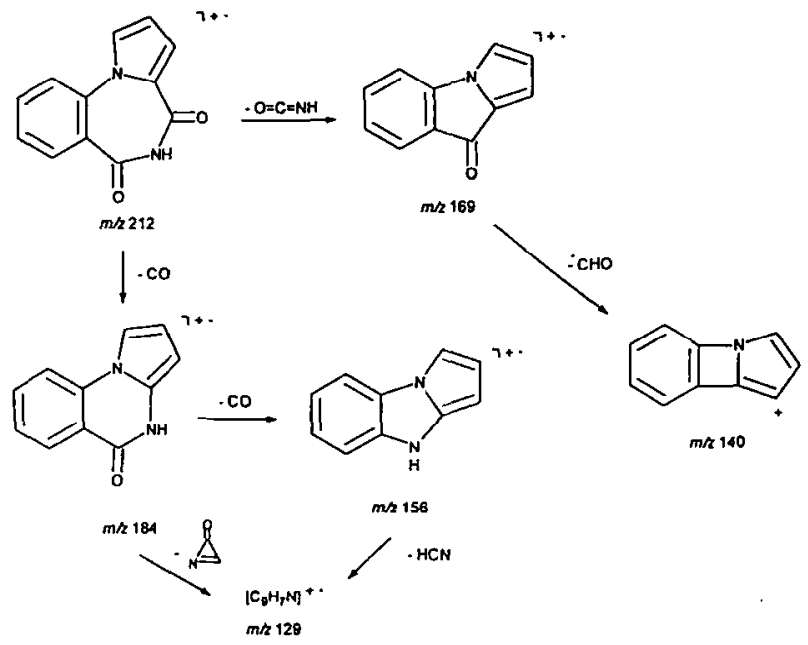

Figure 8. Fragmentation pathways that occur in the source region for compound 3 .

thus particularly useful in this study to confirm the nature of fragment ions and to rationalize the fragmentation pathways.

$[\mathrm{M}]^{+}$primarily fragments in the source to yield ions at $m / z 184$ and 169. HRMS shows that these ions are single peaks due to the losses of $\mathrm{CO}$ and $\mathrm{CONH}$, respectively (Table 1). These fragmentations (Figure 8) produce contractions of the seven-membered ring that yield annelated quinazolinone and indolone derivatives respectively. In the MIKE spectrum (Figure 4, bottom) the ion $[\mathrm{M}-\mathrm{CONH}]^{+\cdot}$ is the most intense metastable peak and it appears as a Gaussian-type peak. The loss of isocyanic acid from $[\mathrm{M}]^{+}$, also observed as the most abundant metastable decomposition in the MIKE spectrum of 1 , is thus highly favored in 4-one derivatives, which allows discrimination in the metastable spectra of the position of the carbonyl group in the seven-membered ring. Another metastable decomposition consists of the loss of $\mathrm{CO}$ and is represented by a peak at $m / z$ 184. The kinetic energy releases $T_{0.5}$ associated with the two metastable processes are 73 and $180 \mathrm{meV}$, respectively.

The MIKE spectrum of the fragment ion [M -28$]^{+\cdot}$ (Figure 6, bottom), in this compound entirely due to the loss of $\mathrm{CO}$, shows the loss of a hydrogen radical and a further prominent loss of $\mathrm{CO}$ that yields a peak at $m / z 156$ (inset in Figure 6, bottom) with a $T_{0.5}$ value equal to $400 \mathrm{meV}$. This value is much higher

Table 2. Doubly charged ion data from compounds 1-3

\begin{tabular}{|c|c|c|c|c|c|c|}
\hline \multirow[b]{2}{*}{ Composition } & \multicolumn{3}{|c|}{ Accurate mass (error $\times 10^{3}$ ) } & \multicolumn{3}{|c|}{ Relative intensity $(\%)$} \\
\hline & 1 & 2 & 3 & 1 & 2 & 3 \\
\hline$[\mathrm{M}]^{2+}$ & $99.0389(1.5)$ & $99.0392(0.9)$ & & 1.5 & 1.8 & \\
\hline$[\mathrm{M}-\mathrm{CO}]^{2+}$ & $85.0417(0.9)$ & $85.0418(0.8)$ & $92.0315(0.7)$ & 4.5 & 3.9 & 2.8 \\
\hline$[\mathrm{M}-\mathrm{CONH}]^{2+}$ & & & $84.5261(0.6)$ & & & 1.8 \\
\hline$[\mathrm{M}-\mathrm{CHO}]^{2+}$ & & $84.5379(0.8)$ & & & 2.6 & \\
\hline$[\mathrm{M}-2 \mathrm{CO}]^{2+}$ & & & $78.0343(0.1)$ & & & 1.4 \\
\hline$\left[\mathrm{C}_{10} \mathrm{H}_{7} \mathrm{~N}\right]^{2+}$ & & $70.5288(0.2)$ & $70.5284(0.5)$ & & 1.8 & 5.6 \\
\hline
\end{tabular}


than that relevant to the decomposition by loss of $\mathrm{CO}$ directly from the molecular ion of $3\left(T_{0.5}=180 \mathrm{meV}\right)$. On the other hand, it is very close to the $T_{0.5}$ value measured for the loss of CO from [M] ${ }^{+\cdot}$ of $\mathbf{1}\left(T_{0.5}=385\right.$ $\mathrm{meV}$ ). A minor peak at $\mathrm{m} / \mathrm{z} 129$, attributable to the loss of $\mathrm{C}_{2} \mathrm{HNO}$, a neutral species with a possible azirinone structure, is also present. Azirinone derivatives are involved in the fragmentation processes of lactams [26]. A related azirinone positive ion also was found in the mass spectrum of the 1-benzyl-3H-1,4benzodiazepin- $(1 \mathrm{H}, 4 \mathrm{H})-2,5$-dione derivative [6].

With regard to the assignment of the elemental composition to fragment ions formed in the source region, high-resolution mass measurements performed at resolution $8000 M / \Delta M$ (10\% valley) showed a large peak at $\mathrm{m} / z 129$ and did not allow determination of an acceptable accurate mass. This could be due to an unresolved multiplet of different ions whose mass-tocharge ratio values differ by less than $125 \mathrm{ppm}$. In fact, from examination of parent-daughter relationships and neutral mass losses, the ion at $m / z 129$ could originate both from the $[\mathrm{M}-\mathrm{CO}]^{+\cdot}$ ion by loss of $\mathrm{C}_{2} \mathrm{HNO}$ or from $[\mathrm{M}-2 \mathrm{CO}]^{+}$by elimination of $\mathrm{HCN}$. These processes yield two different ionic species with elemental composition $\left[\mathrm{C}_{9} \mathrm{H}_{7} \mathrm{~N}\right]^{+}$and $\left[\mathrm{C}_{8} \mathrm{H}_{5} \mathrm{~N}_{2}\right]^{+}$, respectively, whose mass-to-charge ratio values differ by $97 \mathrm{ppm}$. The increase of the resolution to $20,000 \mathrm{M} / \Delta M$ (10\% valley) has allowed good separation of these two components, which are present with a 7:3 intensity ratio, where $\left[\mathrm{C}_{9} \mathrm{H}_{7} \mathrm{~N}\right]^{+}$is the most abundant (Table 1).

Doubly charged ions. The presence of fused heterocyclic systems facilitates the formation of multiply charged ions. As an example, doubly charged ions have been described in the spectra of 3-phenyl-2,1benzisoxazoles [32]. Doubly charged ions present in the spectra of compounds 1-3 are reported in Table 2. They have been confirmed by their isotopic peaks and by accurate mass measurements. The molecular ions of 1 and 2 are both present as doubly charged ions, whereas that of 3 is not detectable as $[\mathrm{M}]^{2+}$. It is noteworthy that, with the exception of the loss of $\mathrm{CONH}$ from the molecular ion of 3 , doubly charged ions produced by losses of nitrogen-containing species are not observed. In particular, losses of ${ }^{\circ} \mathrm{CHNH}$ and $\mathrm{CH}_{2} \mathrm{NH}$, involved in the fragmentation patterns of singly charged ions from 1 and 2, do not occur for doubly charged ions. This suggests that the two positive charges are localized mainly on the nitrogen atoms, in agreement with the general tendency for heteroatoms, and nitrogen in particular, to bear the charges in doubly charged ions [1].

\section{Molecular Orbital Calculations}

Semiempirical molecular orbital calculations were performed on both neutrals and molecular ions of compounds 1-3 by comparison of the MNDO [21] and
AM1 [22] methods. AM1 represents a real improvement over MNDO for molecules that contain both nitrogen and oxygen [22]. With regard to the possible site of ionization, it previously was found that in 1,4-benzodiazepin-2-ones the ionization occurs at the nitrogen atoms [27], which does not seem to be the
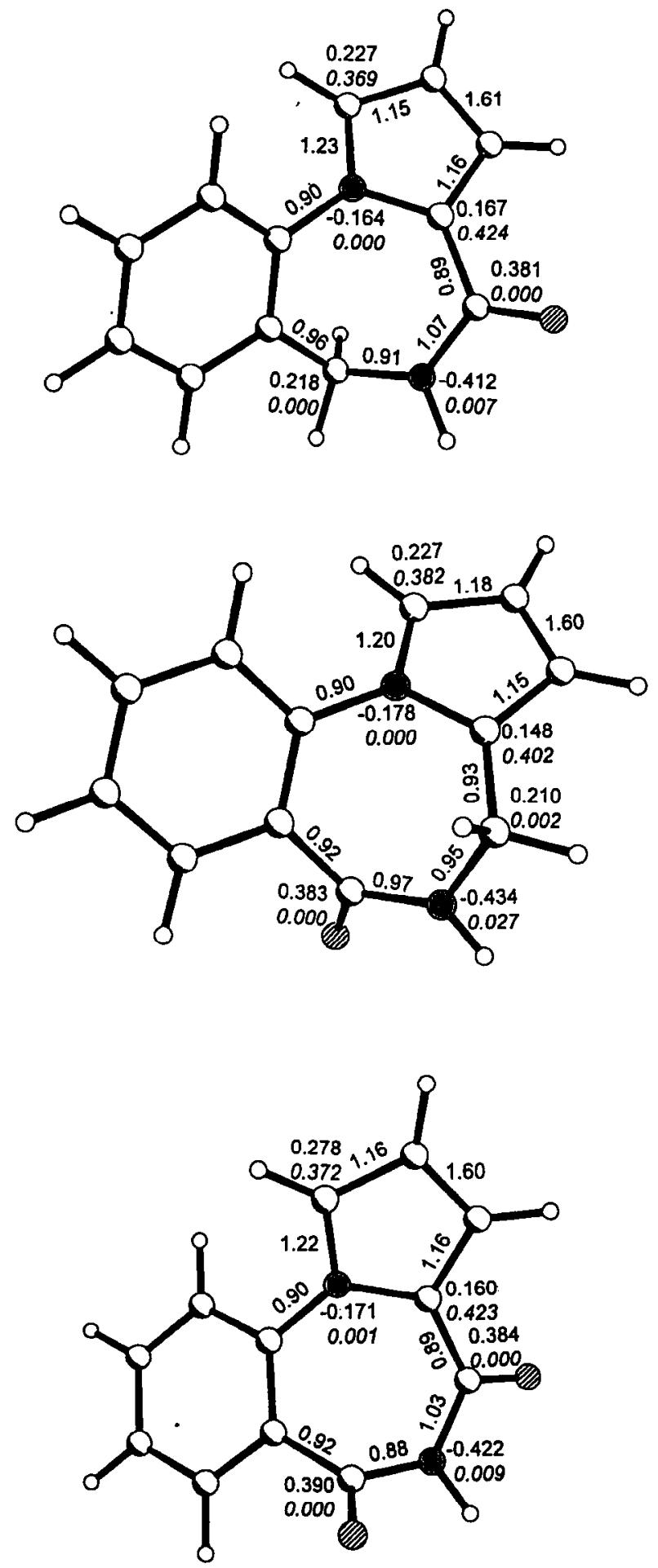

Figure 9. MNDO calculated structures for the molecular ions of isomers 1 (top) and 2 (middle) and compound 3 (bottom). Significant bond orders, charge densities, and free valences (data in Italics) also are reported. 
Table 3. Comparison between the bond orders and their relative changes ( $\Delta \%)^{a}$ calculated by MNDO and AM1 (data in Italics) methods for compounds 1-3

\begin{tabular}{|c|c|c|c|c|c|c|c|c|c|}
\hline & \multicolumn{3}{|c|}{1} & \multicolumn{3}{|c|}{2} & \multicolumn{3}{|c|}{3} \\
\hline & Neutral & $\mathrm{M}^{+\cdot}$ & $\Delta \%$ & Neutral & $M^{+\cdot}$ & $\Delta \%$ & Neutral & $\mathrm{M}^{+\cdot}$ & $\Delta \%$ \\
\hline \multirow[t]{2}{*}{$C(1)-C(2)$} & 1.57 & 1.15 & -26.75 & 1.59 & 1.18 & -25.79 & 1.58 & 1.16 & -25.68 \\
\hline & 1.55 & 1.16 & -25.16 & 1.57 & 1.17 & -25.48 & 1.55 & 1.74 & 12.26 \\
\hline \multirow[t]{2}{*}{$c(2)-C(3)$} & 1.26 & 1.61 & 27.80 & 1.24 & 1.60 & 29.03 & 1.26 & 1.60 & 26.98 \\
\hline & 1.29 & 1.62 & 25.58 & 1.27 & 1.62 & 27.56 & 1.29 & 1.09 & -15.50 \\
\hline \multirow[t]{2}{*}{$C(3)-C(3 a)$} & 1.55 & 1.16 & -25.16 & 1.58 & 1.15 & -27.22 & 1.55 & 1.16 & -25.16 \\
\hline & 1.52 & 1.13 & -25.66 & 1.55 & 1.13 & -27.10 & 1.51 & 1.58 & 4.64 \\
\hline \multirow[t]{2}{*}{$C(3 a)-C(4)$} & 0.93 & 0.89 & -4.30 & 0.95 & 0.93 & -2.11 & 0.94 & 0.89 & -5.32 \\
\hline & 0.94 & 0.89 & -5.32 & 0.96 & 0.95 & -1.04 & 0.95 & 0.92 & -3.16 \\
\hline \multirow[t]{2}{*}{$C(4)-N(5)$} & 1.02 & 1.07 & 4.90 & 0.93 & 0.95 & 2.11 & 0.96 & 1.03 & 7.29 \\
\hline & 1.08 & 1.14 & 5.56 & 0.95 & 0.98 & 3.16 & 1.00 & 1.02 & 2.00 \\
\hline \multirow[t]{2}{*}{$N(5)-C(6)$} & 0.93 & 0.91 & -2.15 & 1.01 & 0.97 & -3.96 & 0.94 & 0.88 & -6.38 \\
\hline & 0.96 & 0.94 & -2.08 & 1.08 & 1.03 & -4.63 & 1.01 & 1.01 & 0.00 \\
\hline \multirow[t]{2}{*}{$C(6)-C(6 a)$} & 0.95 & 0.96 & 1.05 & 0.92 & 0.92 & 0.00 & 0.92 & 0.92 & 0.00 \\
\hline & 0.96 & 0.96 & 0.00 & 0.93 & 0.92 & -1.08 & 0.94 & 0.91 & -3.19 \\
\hline \multirow[t]{2}{*}{$C(6 a)-c(7)$} & 1.40 & 1.41 & 0.71 & 1.39 & 1.41 & 1.42 & 1.39 & 1.42 & 2.16 \\
\hline & 1.40 & 1.40 & 0.00 & 1.38 & 1.40 & 1.45 & 1.36 & 1.50 & 10.29 \\
\hline \multirow[t]{2}{*}{$c(7)-c(8)$} & 1.41 & 1.39 & $-1,42$ & 1.41 & 1.39 & -1.42 & 1.42 & 1.38 & -2.82 \\
\hline & 1.42 & 1.41 & 0.71 & 1.44 & 1.41 & -2.08 & 1.44 & 1.31 & -9.02 \\
\hline \multirow[t]{2}{*}{$C(8)-C(9)$} & 1.40 & 1.41 & 0.71 & 1.41 & 1.42 & 0.71 & 1.40 & 1.42 & 1.43 \\
\hline & 1.40 & 1.40 & 0.00 & 1.39 & 1.41 & 1.44 & 1.38 & 1.31 & -5.07 \\
\hline \multirow[t]{2}{*}{$c(9)-c(10)$} & 1.42 & 1.41 & -0.70 & 1.42 & 1.40 & -1.41 & 1.42 & 1.39 & -2.11 \\
\hline & 1.43 & 1.43 & 0.00 & 1.44 & 1.42 & -1.39 & 1.45 & 1.53 & 5.52 \\
\hline \multirow[t]{2}{*}{$C(10)-C(10 a)$} & 1.37 & 1.38 & 0.73 & 1.37 & 1.39 & 1.46 & 1.37 & 1.40 & 2.19 \\
\hline & 1.36 & 1.36 & 0.00 & 1.35 & 1.37 & 1.48 & 1.34 & 1.17 & -12.69 \\
\hline \multirow[t]{2}{*}{$C(10 a)-C(6 a)$} & 1.36 & 1.34 & -1.47 & 1.35 & 1.33 & -1.48 & 1.35 & 1.32 & -2.22 \\
\hline & 1.35 & 1.35 & 0.00 & 1.35 & 1.34 & -0.74 & 1.36 & 1.17 & -13.97 \\
\hline \multirow[t]{2}{*}{$C(10 a)-N(11)$} & 0.96 & 0.90 & -6.25 & 0.96 & 0.90 & -6.25 & 0.96 & 0.90 & -6.25 \\
\hline & 0.98 & 0.92 & -6.12 & 0.98 & 0.92 & -6.12 & 0.99 & 1.22 & 23.23 \\
\hline \multirow[t]{2}{*}{$N(11)-C(1)$} & 1.13 & 1.23 & 8.85 & 1.12 & 1.20 & 7.14 & 1.13 & 1.22 & 7.96 \\
\hline & 1.16 & 1.24 & 6.99 & 1.14 & 1.23 & 7.89 & 1.16 & 0.99 & -14.66 \\
\hline \multirow[t]{2}{*}{$N(11)-C(3 a)$} & 1.08 & 1.15 & 6.48 & 1.08 & 1.17 & 8.33 & 1.07 & 1.15 & 7.48 \\
\hline & 1.10 & 1.18 & 7.27 & 1.11 & 1.19 & 7.21 & 1.09 & 1.06 & -2.75 \\
\hline \multirow[t]{2}{*}{$C(4)-0$} & 1.81 & 1.83 & 1.10 & & & & 1.85 & 1.87 & 1.08 \\
\hline & 1.75 & 1.77 & 1.14 & & & & 1.79 & 1.84 & 2.79 \\
\hline \multirow[t]{2}{*}{$c(6)-0$} & & & & 1.84 & 1.89 & 2.72 & 1.90 & 1.96 & 3.16 \\
\hline & & & & 1.76 & 1.83 & 3.98 & 1.81 & 1.86 & 2.76 \\
\hline
\end{tabular}

${ }^{a} \Delta \%$ values are referenced to the neutral and defined as $\Delta \%=\left[[\text { b.o. })^{\text {molecular ion }}-(\text { b.o. })^{\text {neutral }}\right] /$ b.o. $\left.)^{\text {noutral }}\right] \times 100$.

case for compounds 1-3. In fact the calculations suggest (Figure 9) that the free valences on $N(5)$ and $N(11)$ are very close to zero, which indicates that the unpaired electron does not reside on these atoms. Furthermore, their charge densities do not show relevant variations between the neutral molecule and the radical ion. In addition, $C(1)$ and $C(3 a)$ show the highest free valences (Figure 9) and it is estimated that the unpaired electron resides for about $80 \%$ of its time on these atoms. From examination of the charge densities, it appears that the highest positive charge is located at $C(4)$ in 1 and at $C(6)$ in 2 and 3. From these data it is reasonable to suppose that the one-electron removal involves the pyrrole moiety, which yields distonic molecular ions for compounds 1-3. Examples of distonic ions in the mass spectra of benzodiazepines already have been reported $[6,14]$.

The study of bond orders is an useful tool in the interpretation of primary fragmentation processes [33]. With regard to isomers 1 and 2, for a given bond, both MNDO and AM1 calculate very close bond orders (Table 3). The data show that, owing to the ionization process, the largest variations are produced in the pyrrole moiety. In fact the double bond characters for the $C(1)-C(2)$ and $C(3)-C(3 a)$ bonds, observed in the neutrals, are lost in the molecular ions. Further- 
more, $\mathrm{C}(2)-\mathrm{C}(3)$ shows a significant strengthening; its bond order is equal to 1.2 in the neutrals and 1.6 in $[\mathrm{M}]^{+}$. The largest difference between the two semiempirical methods resides in the calculations of the bond orders in the pyrrole moiety. In fact, whereas for compounds 1 and 2 both methods predict quite similar values, for 3, AM1 predicts a strengthening of the $C(1)-C(2)$ and $C(3)-C(3 a)$ bonds and a weakening of $C(2)-C(3)$ moving from the neutral to the molecular ion, an opposite trend to that calculated by MNDO (Table 3). In the molecular ion of isomer 1 (Table 3, Figure 9, top), the lowest bond order (b.o.) is predicted for the $C(3 a)-C(4)$ bond (b.o. 0.89), which indicates a possible site for the seven-membered ring to open. It is noteworthy that the $\mathrm{C}(4)-\mathrm{N}(5)$ bond undergoes a strengthening in the molecular ion of 1 [b.o. 1.07 (MNDO) and 1.14 (AM1)] with respect to the neutral molecule, whereas the bond order for $N(5)-C(6)$ shows only minor variations (Table 3 ). Similarly, owing to one-electron removal, an increase of the $\mathrm{C}(4)-\mathrm{N}(5)$ bond order and a weakening (b.o. 0.88) for the other $\mathrm{C}(=\mathrm{O})-\mathrm{N}(-\mathrm{H})$ bond, that is, $C(6)-N(5)$, are predicted for compound 3 by the MNDO method (Table 3, Figure 9, bottom). On the other hand, the only $\mathrm{C}(=\mathrm{O})-\mathrm{N}(-\mathrm{H})$ bond in compound 2, namely, $C(6)-N(5)$, shows a weakening as it goes from the neutral molecule to the molecular ion (Figure 9, middle), whose bond order is estimated to be 0.97 by MNDO and 1.03 by AM1. These results are in good agreement with the mass spectrometric data, which show fragmentation by loss of $\mathrm{CONH}$ from the molecular ion of $\mathbf{1}$ and 3 , but not from that of 2 .

\section{Conclusions}

Mass spectrometry has been shown to be a suitable tool for the identification and characterization of the pyrrolobenzodiazepines $1-3$, which are precursors of biologically active compounds. High-resolution and tandem mass spectrometry have allowed differentiation and distinction of the positional isomers 1 and 2 in the gas phase. This study has evidenced differences in composition and abundance of isobaric ions as well as different metastable decompositions for the two isomers with regard to both their molecular and most abundant fragment ions. The distinction of the position ( 4 or 6) of the methylene group in the benzodiazepine ring of compounds 1 and 2 can be made easily through the study of their mass spectra or the metastable MIKE spectra produced by their molecular or most intense fragment ions. In particular, the process that yields the $[\mathrm{M}-\mathrm{CONH}]^{+\cdot}$ ion is highly favored in the MIKE spectra of compounds 1 and 3 , where both have a carbonyl group at position 4 . On the other hand, the MIKE spectrum of compound 2 shows a very abundant $[\mathrm{M}-\mathrm{H}]^{+\cdot}$ ion and a triplet at $m / z 169,170,171$ that is not detectable in the MIKE spectra of compounds 1 and 3. Furthermore, it is also possible to distinguish isomers 1 and 2 by the study of the MIKE and $E / Q$ spectra produced by their [ $\mathrm{M}-28]$ fragment ions formed in the source.

A theoretical approach that consists of semiempirical molecular orbital calculations, which have been carried out by comparison of the MNDO and AM1 methods, has provided information on the ionization process as well as on the fragmentation pathways of compounds 1-3. In particular, the calculations suggest the formation of distonic molecular ions for 1-3, in which the unpaired electron resides on the pyrrolo and the positive charge is located on the seven-membered ring.

\section{Acknowledgments}

G.G. wishes to thank the Commission of the European Community for a fellowship (ERB-CIPA-CT-92-1506) in the ambit of Community's Action for Cooperation in Science and Technology with Central and Eastern Europe Countries. The Central Research Institute for Chemistry of the Hungarian Academy of Sciences and Dr. K. Vékey also are acknowledged for availability of the ZAB 2-SEQ instrument.

\section{References}

1. Cooks, R. G.; Beynon, J. H.; Caprioli, R. M.; Lester, G. R. Metastable Ions; Elsevier Scientific: Amsterdam, 1973.

2. Bush, K. L.; Glish, G. L.; McLuckey, S. A. Mass Spectrometry/Mass Spectrometry: Techniques and Applications of Tandem Mass Spectrometry; VCH: New York, 1988.

3. Rall, T. W. In The Pharmacological Basis of Therapeutics, 8th ed.; Goodman Gilman, A.; Rall, T. W.; Nies, A. S.; Taylor, P., Eds.; Pergamon: New York, 1990; pp. 346-358.

4. Schütz, H. Benzodiazepines; Springer-Verlag: Berlin, 1982, and references cited therein.

5. Gioia, B.; Arlandini, E.; Giacconi, P.; Rossi, E.; Stradi, R. Biomed. Mass Spectrom. 1984, 11, 408-414.

6. Mohiuddin, G.; Reddy, P. S.; Ahmed, K.; Ratnam, C. V. Org. Mass Spectrom. 1985, 20, 787-788.

7. Chai, W.-G.; Wang, G.-H.; Jin, S.; Lin, Z.-M.; Liu, P. Org. Mass Spectrom. 1987, 22, 660-664.

8. Cortés, E.; Martínez, R.; Hernández, R. Org. Mass Spectrom. 1989, 24, 276-278.

9. Ghezzo, E.; Traldi, P.; Minghetti, G.; Cinellu, M. A.; Bandini, A. L.; Banditelli, G.; Zecca, L. Rapid Commun. Mass Spectrom. 1990, 4, 314-317.

10. Schwartz, M. A.; Bommer, P.; Vane, F. M. Arch. Biochem. Biophys. 1967, 121, 508-516.

11. Borchers, F.; Achtert, G.; Hausleiter, H. J.; Zeugner, H. Eur. J. Drug Metab. Pharmacokin. 1984, 9, 325-346.

12. Geneste, P.; Kamenka, J.-M.; Vidal, Y. Org. Mass Spectrom. 1978, 13, 141-154.

13. Caldwell, G. W.; Kukla, M. J.; Masucci, J. A.; Breslin, H. J.; Jones, W. J.; Gauthier, D. A.; Fedde, C. L. Org. Mass Spectrom. 1991, 26, 97-99.

14. Rubino, F. M.; Zecca, L.; Mascaro, P.; Hunkeler, W. Org. Mass Spectrom. 1991, 26, 636-644.

15. Cortés, E.; Martínez, R.; Ugalde, M.; Maldonado, N. Org. Mass Spectrom. 1991, 26, 113-115.

16. Arellano, M. R.; Martínez, R.; Cortés, E. J. Heterocyclic Chem. 1982, 19, 321-326.

17. Cortés, E.; Martínez, R.; Zarza, A. J. Heterocyclic Chem. 1983, $20,1615-1620$. 
18. Cortés, E.; Cortés, R.; Rojas, R. Org. Mass Spectrom. 1992, 27, 619-620.

19. Corelli, F.; Massa, S.; Stefancich, G.; Ortenzi, G.; Artico, M.; Pantaleoni, G. C.; Palumbo, G.; Fanini, D.; Giorgi, R. Eur. J. Med. Chem.-Chim. Ther. 1986, 21, 445-449.

20. Anzini, M.; Corelli, F.; Cagnotto, A.; Skorupska, M. Med. Chem. Res. 1993, 3, 249-256.

21. Dewar, M. J. S.; Thiel, W. J. Am. Chem. Soc. 1977, 99, 4899-4906.

22. Dewar, M. J. S.; Zoebisch, E. G.; Healy, E. F.; Stewart, J. J. P. J. Am. Chem. Soc. 1985, 107, 3902-3909.

23. Corelli, F.; Massa, S.; Pantaleoni, G. C.; Palumbo, G.; Fanini, D. Il Farmaco, Ed. Sci. 1984, 39, 707-717.

24. Stewart, J. P., F. J. Seiler Research Laboratory, U.S. Air Force Academy, Colorado Springs, 1987.

25. Bischof, P.; Friedrich, G. J. Comput. Chem. 1982, 3, 486-494.

26. Duffield, A. M.; Budzikiewicz, H.; Djerassi, C. J. Am. Chem. Soc. 1964, 86, 5536-5541.
27. Sadée, W. J. Med. Chem. 1970, 13, 475-479 and references cited therein.

28. Fryer, R. I.; Earley, J. V.; Sternbach, L. H. J. Org. Chem. 1969, 34, 649-654.

29. Benz, W.; Vane, F. M.; Rapp, U. Org. Mass Spectrom. 1979, 14, 154-159.

30. Aiello, E.; Dattolo, G.; Cirrincione, G.; Plescia, S.; Daidone, G. J. Heterocyclic Chem. 1979, 16, 209-211.

31. Holmes, J. L.; Terlouw, J. K. Org. Mass Spectrom. 1980, 15, 383-396.

32. Dyall, L. K., Karpa, G. J. Org. Mass Spectrom. 1989, 24, 70-73.

33. (a) Somogyi, Á.; Gömöry, A.; Vékey, K.; Tamás, J. Org. Mass Spectrom. 1991, 26, 936-938; (b) Somogyi, Á.; Wysocki, V. H.; Mayer, I. I. Am. Soc. Mass Spectrom. 1994, 5, 704-717; (c) McCormack, A. L.; Somogyi, Á; Dongré, A. R.; Wysocki, V. H. Anal. Chem. 1993, 65, 2859-2872; (d) Giorgi, G.; Ponticelli, F.; Czira, G.; Vékey, K. J. Am. Soc. Mass Spectrom. 1995, $6,962-971$ 